\title{
"Público" e "privado" nos textos jurídicos francos*
}

\author{
"Public" and "private" \\ in Frankish legal texts
}

\author{
MARCELO CÂNDIDO DA SILVA \\ Professor Associado de História Medieval da Universidade de São Paulo \\ Faculdade de Filosofia Letras e Ciências Humanas, Departamento de História. \\ Avenida Professor Lineu Prestes, 338 - Butantã \\ Cep: 05508-900 \\ candido@usp.br
}

RESUMO O objetivo deste artigo é discutir a dicotomia "público" e "privado", buscando mostrar como ela foi utilizada pela historiografia tradicional para situar cronológica e tematicamente a Alta Idade Média. Isso feito no âmbito de uma evolução geral que teria conduzido, através do triunfo do "público" sobre o "privado", à construção do mundo moderno. Buscar-se-á igualmente, a partir de alguns textos jurídicos, mostrar como essa dicotomia é inviável para a compreensão do mundo franco na Alta Idade Média.

Palavras-chave historiografia, público, francos, textos jurídicos

ABSTRACT The aim of this paper is discuss the "public" and "private" spheres dichotomy, trying to show how it was used by traditional historiography to situate chronologically and thematically the High Middle Ages in an

Artigo recebido em: 05/05/2010. Autor convidado. 
ambit of a general evolution that would have conduced, through the triumph of "public" over "private", for the construction of the modern world. Will also search, from some juridical texts, show how this dichotomy is impossible to the comprehension of the frankish world at the High Middle Ages.

Keywords historiography, public, Franks, legal texts

\section{Introdução}

Os estudos sobre as sociedades da Alta Idade Média constituem, já há alguns anos, uma paisagem em plena mutação. Eles são o terreno da emergência de novas perspectivas sobre fontes já conhecidas: a descoberta, desde o final do século XIX, de alguns textos fiscais (as Contas do Monastério de Tours e uma nova versão do Políptico, de Saint-Rémi de Reims), e também de necrópoles e túmulos de chefes não pode explicar por si só as transformações em tela. Assistimos a um movimento de outra natureza. As fontes disponíveis são reconsideradas, desconstruídas e reconstruídas, ${ }^{1}$ e o próprio termo "fontes" é colocado em questão. ${ }^{2}$ Essa intensa renovação atinge tanto os textos escritos quanto os elementos da cultura material. Os dados arqueológicos, ao invés de pressupostos, são considerados materiais sujeitos a interpretações que se abrem para horizontes até então desconsiderados por historiadores e arqueólogos, como a amizade, a inimizade, a competição, as emoções ou a psicologia social. Paradoxalmente, esse movimento só foi possível graças à crise da História, dos paradigmas e dos objetos de estudo tradicionais do historiador.

Mais do que uma crise da História, o mais correto, aliás, seria falar em crise da História Científica e de seus instrumentais teórico-metodológicos consagrados em boa parte à genealogia do Estado Nacional. Essa crise atingiu em cheio as grandes edições de textos realizadas nesse período (Monumenta Germaniae Historica, Patrologia Latina, dentre outros). ${ }^{3}$

1 A esse respeito, ver LE JAN, Régine. Descontrucionismo e construcionismo nas fontes da Alta Idade Média. Conferência ministrada na abertura do Colóquio Internacional Os medievalistas e suas fontes: a Alta Idade Média. Laboratório de Estudos Medievais (LEME) e Laboratoire de Médiévistique Occidentale de Paris (LAMOP), 7, 8 e 9 de abril de 2009

2 Para uma crítica do termo "fontes", ver os artigos de MORSEL, Joseph. Les sources sont-elles le pain de l'historien? Hypothèses, Paris, n.1, p.263-586, 2003; e de KUCHENBUCH, Léopold. Sources ou documents? Contributions à l'histoire d'une évidence méthodologique, Hypothèses, Paris, n.1, p. 287-315, 2003.

3 Uma das mais importantes edições de textos medievais, os Monumenta Germaniae Historica (MGH) constituem parte essencial do projeto Romântico de recuperação da Idade Média. A divisa da coleção, Sanctus amor patriae dat animum já foi interpretada como prova da marca patriótica associada ao projeto. Essa não é a opinião de $\mathrm{H}$. Fuhrmann: "Cette maxime illustre l'esprit qui présida à la fondation des MGH: 'l'amour de la patrie incite à l'action'. Mais il serait pour le moins aventureux d'identifier purement et simplement cet 'amour de la patrie', qualifié, qui plus est, de saint (Sanctus amor), au patriotisme. Il exprime plutôt la conviction que l'esprit agissant émane du peuple et de la patrie et que seul le renforcement de cet esprit permet d'espérer des résultats. Que la libération de l'esprit populaire' comportât certains dangers pour l'ordre, c'était ce que craignaient avant tout les forces de restauration, 
Muito embora a leitura crítica das edições dos textos medievais não seja um fenômeno recente, era concentrada, pelo menos até os anos 1970, nas questões de erudição. Em 1925, por exemplo, F. Lot mostrou que o texto identificado por A. Boretius e V. Krause como a primeira capitular de Carlos Magno era uma falsificação. ${ }^{4}$ Para F-L. Ganshof, a edição de Boretius e de Krause deixaria a desejar, tanto do ponto de vista da crítica textual, quando do ponto de vista da história do Direito: o aparato crítico seria incompleto e não repousaria em uma classificação metódica dos elementos da tradição manuscrita ou impressa. A crítica contemporânea sustenta que os autores dessas edições foram além de um trabalho de erudição, privilegiando algumas famílias de manuscritos em detrimento de outras, reconstruindo manuscritos a partir da supressão de discrepâncias que, mantidas, permitiriam uma outra compreensão do texto, etc. Essa crítica é acompanhada de um retorno aos manuscritos e da percepção de que um estudo atento dos mesmos pode chamar a atenção para uma série de elementos figurativos e paleográficos que geralmente passam desapercebidos nas edições impressas. ${ }^{5}$ Antes consideradas apenas do ponto de vista da hercúlea tarefa de erudição que as engendrou, as edições de textos medievais constituem-se hoje também em um objeto historiográfico. ${ }^{6}$

A História Política retorna com força, mas ela não é a mesma que foi criticada e destronada pelo movimento dos Annales. A questão colocada por J. Le Goff em seu artigo de 1971, "a História Política ainda é a espinha dorsal da História?", parece ter encontrado sua resposta na multiplicação das pesquisas sobre as elites, os poderes locais, o espaço político, e a renovação do interesse pela diplomacia, pelas normas e pela resolução de conflitos. O campo de estudo do poder estendeu-se para domínios antes inexplorados pelos historiadores, como a construção das identidades, ${ }^{7}$ os

qui venaient tout juste de conquérir ou de reconquérir leurs biens et leurs territoires lors du Congrès de Vienne en 1815". FUHRMANN, Horst. Les premières décennies des Monumenta Germaniae Historica. Francia, v.21, n.1, p. 175-180, 1994.

4 LOT, FERDINAND. LE PREMIER CAPITULAIRE DE CHARLEMAGNE. ANNUAIRE DES ÉCOLE PRATIQUE DES HAUTES ÉTUDES, 1924-1925 ; GANSHOF, FERDINAND-LOUIS. RECHERCHES SUR LES CAPITULAIRES. PARIS: SIREY, P.8.

5 Um bom exemplo desse retorno aos manuscritos é o livro ZERNER, Monique. (org.) Inventar a heresia? Discursos polêmicos e poderes antes da Inquisição. Campinas, LEME/Editora da UNICAMP, 2009, resultado do seminário Heresia, estratégia de escrita e instituição eclesial, acontecido em Nice de 1993 a 1995, e de uma mesa-redonda que se seguiu, em 1996. Os autores optaram por retornar aos textos, narrativos, normativos e polêmicos escritos antes da criação dos tribunais da Inquisição. Poderíamos citar também o artigo de C. Lauranson-Rosaz sobre o Liber Legis Doctorum de Clermont: LAURANSON-ROSAZ, C. Le Bréviaire d'Alaric en Auvergne: le Liber Doctorum de Clermont (ms. 201, anc. 175) de la B.M.I.U. de Clermont-Ferrand. In: ROUCHE, Michel e DUMÉZIL, Bruno. (orgs.) Le Bréviaire d'Alaric. Aux origines du Code Civil, Paris: Presses de l'Université Paris-Sorbonne, 2008, p.241-276.

6 BERGER, Stefan. Introduction: towards a Global History of National Historiographies. In: Writing the Nation. A global perspective. New York: Macmillan, 2007, p.1-29; BERGER, Stefan, The power of national pasts: Writing national history in Nineteenth- and Twentieth-century Europe". In: Writing the Nation. A global perspective, p.30-62.

7 Há uma boa síntese dos debates sobre a construção das identidades em GAZEAU, Véronique; BAUDUIN, Pierre e MODÉRAN, Yves. (dirs.) Identité et Ethnicité. Concepts, débats historiographiques, exemples (IIle-XIIe siècles). Caen: Publications du CRHAM, 2008. 
funerais, ${ }^{8}$ a literatura, os sentimentos, ${ }^{9}$ a amizade, a inimizade, as relações de parentesco e a psicologia familiar. ${ }^{10}$ Até a primeira metade do século $X X$, poucos eram os historiadores que acreditavam que esses fossem loci do poder ou mesmo temas dignos de atenção da História.

O estudo do consenso nos reinos bárbaros tem mostrado que o fenômeno da dominação nas sociedades da Alta Idade Média vai além da simples relação de mando e obediência, consagrada pela teoria clássica do Direito. ${ }^{11}$ A relação governantes/governados não foi a única a ser colocada em xeque na reflexão historiográfica dos últimos trinta anos. Os binômios construídos no âmbito da História Científica e sobre os quais se fundamentavam os estudos sobre a Idade Média (público/privado, racional/irracional, ideal/realidade, clérigo/laico, sagrado/profano, igreja/estado, paz/violência) encontram-se relativizados, e até mesmo abandonados, em proveito de leituras mais nuançadas das concepções e das práticas sociais daquele período. ${ }^{12}$ Ao longo desse trabalho, nos concentraremos em um desses binômios, público/privado, buscando mostrar como ele foi utilizado para situar cronológica e tematicamente a Alta Idade Média no âmbito de uma evolução geral que teria conduzido ao mundo moderno, bem como seus limites nos textos jurídicos francos.

\section{O problema das origens medievais}

Em 1995, ao redigir meu projeto de pesquisa para o ingresso no curso de Mestrado da Universidade Federal de Minas Gerais (UFMG) - um estudo sobre as relações entre o episcopado e a realeza na época carolíngia - incluí as seguintes palavras na justificativa: "O estudo da Idade Média é importante na medida em que ele pode ajudar na compreensão das origens do mundo moderno: é nessa época que elementos fundamentais da modernidade foram constituídos, como a Igreja e o Estado". Esse ponto de

8 TESTART, Alain. Enjeux et difficultés d'une archéologie sociale du funéraire. In: Pratiques funéraires et sociétés. Dijon: Éditions de l'Université de Dijon, 2007, p.9-13; TESTART, Alain. Deux politiques funéraires: dépôt ou distribution. In: Archéologie des pratiques funéraires: approche critique. Actes de la table ronde organisée au Centre archéologique européen du Mont Beuvray, en collaboration avec l'UMR 5594 de Dijon (7-9 juin 2001). Glux-enGlenne: Centre archéologique européen, 2004, p.303-310; HALSALL, G. Settlement and social organization: the Merovingian region of Metz. Cambridge: Cambridge University Press, 1995.

9 ROSENWEIN, Barbara. (ed.) Anger's Past: The social uses of an Emotion in the Middle Ages. Ithaca: Cornell University Press, 1998.

10 ROSENWEIN, Barbara. Emotional Communities and the Body. (http://www.kcl.ac.uk/content/1/c6/02/04/95/LondonEmtheBody.pdf).

11 "Merovingian Francia, we now realize, worked by consensus; the Carolingians, far from forging a state, were forever negotiating to stay in power; and the 'feudal anarchy' of the post-Carolingian period worked through informal mechanisms of dispute resolution". ROSENWEIN, Barbara. Writing without fear about early medieval emotions. Early Medieval Europe, v.10, n.2, p. 229-234, 2001). Ver também, WOOD, lan. Kings, kingdoms and consent. In: SAWYER, Peter e WOOD, lan. (eds.) Early Medieval Kingship. Leeds: The Editors, p.3-29.

12 No que se refere às relações entre 1) racional e irracional: COLMAN, Rebecca. Reason and unreason in early medieval law. Journal of Interdisciplinary History, v.4, p. 571-91, 1974; 2) ideal e realidade: MCKITTERICK, Rosamond. Perceptions of Justice in western Europe in the ninth and tenth centuries. La Giustizia nell'Alto Medioevo (secoli IX-XI), Settimane di Studio del Centro Italiano di Studi sull'Alto medioevo, p.1075-1102; 3) paz e violência: WALLACE-HADRILL, Jonh-Michael. The Long Haired Kings. Londres: Methuen, 1962. 
vista não era de modo algum original: um grande número de historiadores considerava e ainda considera que o estudo do período medieval constitui um meio eficaz para definir a genealogia ou as raízes da "civilização ocidental" contemporânea, até mesmo para além das fronteiras da Europa. A crise do marxismo, cujo impacto sobre a vida acadêmica brasileira se fez sentir com mais intensidade a partir do início dos anos 1990, contribuiu para que o famoso debate entre Maurice Dobb e Paul Sweezy ${ }^{13}$ caísse no esquecimento, e com isso, a própria ideia de uma ruptura entre o mundo medieval e o mundo moderno ficava em segundo plano, superada entre nós pela tese da "longa Idade Média". Para além de algumas esquematizações manualísticas, a melhor sistematização da tese das origens medievais do Brasil desde os anos 1990 é o livro do historiador mexicano Luis Weckmann, La herencia medieval del Brasil. ${ }^{14}$ A recepção desse livro no Brasil foi, no entanto, bastante morna, o que se deve provavelmente à lembrança ainda viva nos nossos meios universitários da polêmica em torno do "feudalismo brasileiro", e que se terminou com a refutação da idéia de um passado feudal do Novo Mundo.

O debate sobre as influências medievais no Brasil foi, pelo menos até os anos 1970, o monopólio dos especialistas em história colonial: tratava-se então de discutir o caráter feudal da colonização portuguesa na América. A "herança feudal" portuguesa explicaria o atraso do Brasil em engajar-se na via da modernização, diferentemente dos Estados Unidos, por exemplo. Segundo Nelson Werneck Sodré, a sociedade brasileira dos anos 1950 seria ainda marcada pela servidão da população rural, traço típico do feudalismo que, segundo ele, subsistiu às margens do regime escravista. A abolição da escravidão não teria modificado de maneira substancial o regime de possessão da terra, mas, ao contrário, reforçado e ampliado a dominação feudal no campo. ${ }^{15}$ Alberto Passos Guimarães, em sua obra Quatro Séculos de Latifúndio ${ }^{16}$ sustentava que apesar do papel importante desempenhado pelo capital comercial no processo de colonização do Brasil, a sociedade não integrou as características da economia moderna. O capital comercial teria sido submetido à estrutura nobiliárquica e ao poder feudal instaurados na América Portuguesa pelos nobres sem fortuna determinados a reproduzir no Brasil os tempos dourados do "feudalismo clássico". Esse ponto de vista suscitou numerosas críticas, inclusive no seio da historiografia marxista. Os trabalhos escritos desde os anos 1970 colocaram em dúvida o suposto caráter "feudal" da

13 Esse debate começou com as críticas de Paul Sweezy ao livro de DOBB, Maurice. Studies in the Development of Capitalism. Londres: Routledge and Kegan Paul, 1946, e teve como cenário principal a Revista Science and Society.

14 WECKMANN, Luis. La herencia medieval del Brasil. México: Fondo de Cultura Económica, 1993.

15 SODRÉ, Nelson Werneck. Formação Histórica do Brasil. São Paulo: Brasiliense, 1962.

16 GUIMARÃES, Alberto Passos. Quatro Séculos de Latifúndio. Rio de Janeiro: Paz e Terra, 1963. 
colonização portuguesa no Brasil, ao mesmo tempo em que sublinhavam que essa última se inscrevia inteiramente no contexto do mercantilismo e da consolidação de uma "economia-mundo" européia.

Nesse sentido, dois livros de Luis Weckmann, La herencia medieval del México (publicado em 1983), ${ }^{17}$ e La herencia medieval del Brasil (de 1993), possuem todas as características de um formidável retrocesso historiográfico. Segundo esse autor, não teria havido na Idade Média um "outono da Idade Média". Os espanhóis e os portugueses teriam podido transmitir ao Novo Mundo instituições e modelos da Idade Média que ainda estavam em vigor na Península Ibérica. Deste lado do Atlântico, o "outono da Idade Média" teria ocorrido no século XVII. No que diz respeito precisamente ao Brasil, Weckmann estabelece um quadro bastante exaustivo - e em boa medida tão desconexo quanto amplo - do que ele chama de "frutos tardios do espírito medieval": os conselhos municipais, a devoção à Virgem, a nobreza, a Ordem do Cristo, a encomienda, a música, as danças e os jogos, a navegação, os regulamentos administrativos e comerciais, o artesanato, as técnicas de produção, a Escolástica, o ensino, os debates teológicopolíticos, as múltiplas manifestações da região cristã, tanto do ponto de vista litúrgico quanto do ponto de vista das numerosas formas de devoção. ${ }^{18}$ Segundo Weckmann, a conquista e o povoamento da América significaram, além da transmissão das instituições medievais e sua adaptação ao Novo Mundo, o renascimento de velhas instituições já em decadência na Europa. No Brasil, o regime das capitanias hereditárias, em vigor entre os anos 1530 e 1549, teria instituído os privilégios senhoriais e feudais. É pouco provável que se possa atribuir um tal peso e uma tal natureza a uma experiência não somente cronologicamente restrita, mas também estabelecida por iniciativa de um poder centralizado.

Os paralelismos que Weckmann estabelece entre a Idade Média e a história colonial brasileira se assemelham em muito à pura analogia. É o caso, por exemplo, do conflito ocorrido em Salvador em meados do século $\mathrm{XVI}$ entre o governador português e o bispo da cidade; segundo o autor, um "eco" da Querela das Investiduras!19 Ou ainda, quando ele menciona os viajantes portugueses do início do século XVI que teriam observado leões na floresta brasileira: isso seria a prova de que esses viajantes estavam guiados por uma "concepção medieval do mundo". Não há muitas dúvidas de que os exploradores portugueses, espanhóis, franceses, genoveses ou ingleses tenham enxergado a paisagem do Novo Mundo a partir de sua própria experiência, mas daí a qualificá-la de especificamente medieval

\footnotetext{
17 La herencia medieval del Mexico. Mexico, 1983, 2 v. Esse livro conheceu certo sucesso fora das fronteiras do México e da América Latina por meio de sua tradução para o inglês por Frances M. López-Morillas. WECKMANN, Luis The medieval heritage of Mexico, New York, Fordham University Press, 1992.

18 WECKMANN, Luis. La herencia medieval del Brasil, p.18.

19 WECKMANN, Luis. La herencia medieval del Brasil, p.24.
} 
vai uma distância que a análise do autor é incapaz de encurtar ou tornar minimamente inteligível ao leitor.

Esse ponto de vista sobre as origens medievais do Novo Mundo constitui também uma maneira de legitimar os estudos sobre a Idade Média européia no Brasil e na América Latina. De fato, ao enfatizarem as origens medievais da sociedade mexicana ou brasileira, os medievalistas latino-americanos podem assim melhor justificar a utilidade ou mesmo o sentido de seu trabalho, não somente diante de seus compatriotas e de suas agências de fomento, mas também diante de seus colegas europeus. Nas páginas seguintes, gostaria, a partir de uma leitura crítica da historiografia recente a respeito das relações entre Alta e Baixa Idade Média, bem como de alguns textos produzidos entre os séculos VI e IX, de apresentar as razões que me conduziram a uma postura crítica face às relações tradicionalmente estabelecidas entre Idade Média e o mundo moderno.

Não podemos subestimar o papel desempenhado pela Idade Média no debate político contemporâneo e na fabricação das identidades, sejam elas nacionais, regionais ou européias. No continente europeu, as "continuidades medievais" são muitas vezes discursos destinados a legitimar partidos, grupos religiosos ou étnicos. De fato, a interpretação do período compreendido entre a desagregação do Império Romano do Ocidente e a formação dos reinos bárbaros tornou-se o pilar do discurso político europeu pelo menos desde o século XIX. A Idade Média (mais particularmente, a Alta Idade Média) foi considerada como parte constitutiva da construção das diversas identidades nacionais européias. Em 1963, André Loyen publicou um artigo cujo título era Résistents et collaborateurs en Gaule à l'époque des grandes invasions; ${ }^{20}$ em 1989, o livro de Patrick Geary intitulado Before France and Germany foi traduzido na França com o título Naissance de la France, e isso contra a opinião do autor. ${ }^{21}$ Esses dois exemplos - e poderíamos citar outros - mostram que os paralelismos com a Idade Média podem ser ao mesmo tempo o fruto da decisão de um editor e a projeção sobre a história medieval da ideia de nação e dos conceitos que o acompanham. Os primeiros séculos da Idade Média constituem também o pilar de uma idéia de Europa e, sobretudo, de "civilização ocidental" que vai muito além das fronteiras da Europa Política. Ao longo dos últimos anos, tanto nas obras quanto nos colóquios consagrados à Alta Idade Média, podemos observar a preeminência de uma perspectiva européia em detrimento das perspectivas nacionais. As origens medievais da Europa ocupam hoje muito

20 LOYEN, André. Résistants et collaborateurs en Gaule à l'époque des grandes invasions. Bulletin de l'Association Guilaume Budé, v.IV, n.22, p.437-450, 1963.

21 GEARY, Patrick. Naissance de la France: le monde Mérovingien. Paris, Flammarion, 1989. Ver GEARY, Patrick. Before France and Germany. The creation and transformation of the Merovingian world. Oxford: Oxford University Press, 1988. 
mais a atenção dos historiadores do que as origens medievais da França ou da Alemanha.

Há algumas décadas, os especialistas da Alta Idade Média dos dois lados do Atlântico, especialmente em Viena e em Toronto (com diferenças importantes, é preciso reconhecer), têm mostrado como os historiadores instrumentalizaram, desde o século XIX, a Alta Idade Média com fins identitários e nacionalistas. ${ }^{22}$ Graças a esses trabalhos, a "Germânia", essa "incubadora" de povos, de instituições e de costumes que teriam presidido a formação dos reinos bárbaros, foi mostrada como uma construção de eruditos europeus, especialmente alemães, preocupados em definir o caráter nacional da identidade germânica. Segundo esses eruditos, a identidade germânica teria repousado em uma base étnica comum, isto é, o mesmo sangue, uma mesma cultura e uma mesma língua. Para completar esse modelo, eles buscaram uma origem geográfica comum a todos os povos germânicos, concluindo, às vezes com o apoio de textos antigos, que eles vieram da Escandinávia, a partir de onde, por vagas sucessivas, teriam vindo conquistar o Império Romano. As críticas dos historiadores e arqueólogos das chamadas Escola de Viena e Escola de Toronto, ainda que em graus variados, lançaram o descrédito sobre esse modelo explicativo. Os estudos sobre a etnogênese dos bárbaros mostram que os povos chamados de "francos" ou "godos" pelos romanos não eram entidades naturais ou geneticamente homogêneas, mas categorias cultural e politicamente construídas que reagrupavam pessoas que podiam ser muito diferentes umas das outras e que podiam ao mesmo tempo não ser tão diferentes daqueles que eram consideradas estrangeiras a essas mesmas categorias. Herwig Wolfram e Walter Pöhl afirmam que os povos bárbaros eram inicialmente constituídos por grupos restritos (os "face-to-face grooups" ou "núcleos de tradição") que contavam com algumas milhares, algumas centenas ou mesmo algumas dezenas de pessoas. Ao longo das migrações, esses grupos recebiam a adesão de populações diversas que adotavam o nome e as tradições dos grupos originais. ${ }^{23}$ Walter Goffart foi ainda mais longe, e colocou em dúvida a própria existência desses "núcleos de tradição". De fato, é muito difícil identificar esses núcleos através dos elementos da

22 WENSKUS, Reinhard. Stammesbildung und verfassung: Das werden der frühmittelalterlichen gentes. Cologne, 1961; WOLFRAM, Herwig. The Roman Empire and its Germanic Peoples. Londres/Berkeley/Los Angeles, 1997; WOLFRAM, Herwig. Die Germanen. Munich, 1995; WOLFRAM, Herwig. Die Goten. Von den Anfängen bis zur Mitte des sechsten Jahrhunderts. Entwurf einer historischen Ethnographie. Munich, 2001; PÖHL, Walter e REIMITZ, Helmut. (eds.) Strategies of distinction: the construction of ethnic communities, 300-800. Leiden, 1998; GOFFART, Walter. Barbarians and Romans (A.D. 418-584): the Techniques of accommodation. Princeton: Princeton University Press, 1980.

23 Uma das melhores introduções a esse modelo se encontra no artigo de PÖHL, Walter. Aux origines d'une Europe ethnique. Transformations d'identité entre Antiquité et Moyen Âge. Annales H.S.S., Paris, v.60, n.1, p.183-208, 2005. 
cultura material. ${ }^{24}$ Apesar das diferenças entre elas - por vezes expressas de maneira radical - essas duas "escolas" estão de acordo em considerar que os nomes, os mitos de origem ${ }^{25} \mathrm{e}$ as leis daquilo que designamos de "povos bárbaros" constituem discursos produzidos por elites militares e políticas que reivindicavam um poder exclusivo sobre certas partes da Res publica. Os cronistas da Idade Média e os historiadores do Antigo Regime tomaram esses "discursos" como a prova da existência de sólidas comunidades étnicas nos fundamentos dos reinos que levavam os nomes dessas comunidades. Os historiadores do século XIX, por sua vez, estabeleceram uma filiação direta entre as identidades bárbaras do século $V$ e as identidades nacionais de sua época.

A segunda razão de minha desconfiança em relação às conexões estabelecidas entre a Idade Média e o mundo moderno é a preocupação com as "especificidades" das sociedades da Alta Idade Média, sobre as quais gostaria de me deter agora.

Há pouco espaço nas sínteses recentes sobre o período medieval para um olhar sobre as especificidades de seus primeiros séculos. Em seu livro, A civilização feudal, Jérôme Baschet consagrou um capítulo essencialmente cronológico à Alta Idade Média. ${ }^{26} \mathrm{O}$ cerne de sua reflexão repousa sobre a dinâmica da sociedade medieval, cujos traços evidentes ele situa não antes do século XI. Joseph Morsel, em seu livro L'aristocratie médiévale (2004) e, sobretudo, em L'Histoire (du Moyen Âge) est un sport de combat (2007), ${ }^{27}$ atribui um lugar mais importante à Alta Idade Média, que ele integra na dinâmica de um duplo processo de "desparentalização" e de "espacialização", cujo ponto de inflexão seria o século XI. A "desparentalização" se traduziria pelo fato de que as relações de parentesco não seriam mais "primo-estruturantes" mas "exo-estruturadas". Entretanto, podemos nos questionar se o parentesco nas sociedades da Alta Idade foi tão fundamentalmente primo-estruturantes. O principal problema está na grande dificuldade de identificar claramente nos textos, antes do século VIII e mesmo antes do século IX, os contornos dos grupos de parentesco. É preciso lembrar que as primeiras linhagens só podem ser claramente identificadas nos textos a partir do século X, como bem mostrou Régine Le Jan. ${ }^{28} \mathrm{Um}$ bom exemplo nesse sentido está no episódio conhecido como as bella civilia de Tours,

24 CURTA, Florin. Some remarks on ethnicity in Medieval Archaeology. Early Medieval Europe, v.15, n.2, p.159-185, 2007.

25 Sobre a relação entre as histórias e a construção das identidades bárbaras, ver COUMERT, Magali. Origines des peuples. Les récits du Haut Moyen Age occidental (550-850). Paris: Institut d'Études Augustiniennes, 2007.

26 BASCHET, Jérôme. A civilização feudal. Do Ano Mil à conquista da América. São Paulo: Editora Globo, 2006.

27 MORSEL, Joseph. L'aristocratie médiévale, Ve-XVe siècle. Paris: Armand Colin, 2004; MORSEL, Joseph e DECOURTIEUX, Christine (colab), L'Histoire (du Moyen Âge) est un sport de combat... Réflexions sur les finalités de l'Histoire du Moyen Âge destinées à une société dans laquelle même les étudiants d'Histoire s'interrogent. Paris, 2007, http://lamop.univ-paris1.fr/W3/JosephMorsel/index.htm.

28 LE JAN, Régine. Famille et pouvoir dans le monde franc (VIIe-Xe siècle). Essai d'anthropologie sociale. Paris: Publications de la Sorbonne, 1995, p.429 e sg. 
descritas por Gregório de Tours (Histórias VII, 47; Histórias IX, 19): não é possível, através do relato do bispo, de estabelecer relações de parentesco no seio de cada grupo que participa do conflito. ${ }^{29}$ Apesar da preocupação de J. Morsel de integrar a Alta Idade Média à sua reflexão, o conceito de "desparentalização" parece demasiadamente amplo e demasiadamente centrado na dinâmica dos séculos XI-XIII para ser um instrumento útil à compreensão das sociedades anteriores ao Ano Mil.

Por outro lado, é difícil não concordar com Jerôme Baschet quando este afirma que é indispensável estabelecer entre a Idade Média e nós uma dupla relação de encadeamento dinâmico e de alteridade. No entanto, também é absolutamente necessário colocar a questão das relações entre as sociedades da Alta e da Baixa Idade Média, destacando a alteridade e a ruptura. Eis o grande desafio dos estudos desse período, concentrar-se nos elementos constitutivos e originais das sociedades dos séculos V-XI, sem no entanto deixar de lado sua dinâmica.

Esse trabalho se iniciou faz muito tempo, notadamente no que diz respeito aos séculos III-VIII. Como contraponto às noções de ruptura e decadência do mundo romano, implícitas na expressão "Baixo Império", a "Antiguidade Tardia" afirmou-se como o elo entre Antiguidade e Idade Média. Embora tenha se popularizado no final do século XIX com as obras do historiador da arte vienense Alois Riegl (Spätantike), é com H.-I. Marrou (Antiquité Tardive) e, sobretudo, com Peter Brown (Later Antiquity), na segunda metade do século XX, que o termo "Antiguidade Tardia" conquistou uma posição de destaque na reflexão historiográfica. Paul Veyne, em seu prefácio do livro de Peter Brown, La genèse de l'Antiquité Tardive, afirma que, uma vez dissipadas o que ele chama de "nuvens fantasmagóricas", aparece o verdadeiro problema, que nada mais tem a ver com a queda de Roma: as inovações, as mutações e a criatividade do mundo romano durante a Antigüidade Tardia, as novas estruturas mentais, sociais, religiosas $^{30}$. Essas leituras sobre a originalidade das sociedades compreendidas entre os séculos III e VIII abordam temas tão amplos quanto as crenças e os estilos de dominação, ${ }^{31}$ a arte e a idéia de Deus. ${ }^{32}$ Ainda que às vezes

29 Ver, por exemplo, DEPREUX, Philippe. Une faide exemplaire? À propos des aventures de Sichaire. Vengeance et pacification aux temps mérovingiens. In: BARTHÉLEMY, Dominique; BOUGARD, François; LE JAN, Régine. (dirs.) La vengeance, 400-1200. Paris: École Française de Rome, 2006, p.65-85; e também, CÂNDIDO DA SILVA, Marcelo. Autoridade pública e violência no período merovíngio: Gregório de Tours e as Bella Civilia. In: LOPES GUIMARÃES, Marcella; FRIGHETTO, Renan. (dirs.) Instituições, poderes e jurisdições. Curitiba: Juruá, 2007, p.181-195.

30 VEYNE, Paul. Préface. In: BROWN, Peter. (org.) Genèse de l'Antiquité tardive. Paris: Gallimard, 1983, p.XV. Claro, há também, antes deles, FUSTEL DE COULANGES, Numa Denis. Histoire des institutions politiques de l'ancienne France. La monarchie franque. Paris: Hachette, 1888, v.3. Fustel de Coulanges é um precursor em vários domínios, e encontramos em sua obra um esforço para compreender a evolução e o lugar específico das sociedades da Alta Idade Média.

31 BROWN, Peter. Genèse de l'Antiquité tardive. Paris: Gallimard, 1983

32 MARROU, Henri-Irénée. Décadence romaine ou Antiquité tardive? (III - Vle siècle). Paris: Seuil, 1977. 
colocada em questão, ou submetidas a interpretações radicalizadas ${ }^{33}$ (como é o caso entre os "hiper-romanistas"), a noção da Antiguidade Tardia teve o mérito de situar a formação dos reinos bárbaros menos como o fim do mundo romano do que como uma reorganização de forças em sociedades ainda marcadas pela influência do Império Romano, mas profundamente originais.

As sociedades dos primeiros séculos da Idade Média sofrem também da comparação com as sociedades dos séculos XI-XIII e seu duplo "renascimento", urbano e comercial, mesmo que a caracterização das primeiras como uma economia não monetarizada e fechada tenha sido colocada em xeque há tempos. Nesse sentido, Jean-Pierre Devroey, em dois livros publicados respectivamente em 2003 e em 2006, propôs uma síntese sobre os fundamentos materiais, as trocas e as relações sociais da Europa franca, e tudo isso integrando as contribuições da antropologia e da arqueologia. ${ }^{34} \mathrm{Em} 2005$, Chris Wickham publicou um livro no qual propõe uma análise comparativa entre as regiões do Império Romano tardio e do mundo pós-romano, da Dinamarca ao Egito. O livro se concentra nos temas sócio-econômicos clássicos, as finanças públicas, a riqueza e a identidade da aristocracia, a administração pública, a sociedade camponesa, as cidades e as trocas. ${ }^{35}$ Além dessas obras de síntese, é preciso mencionar as pesquisas inter-universitárias levadas a cabo a nível europeu, e que muito contribuíram à consolidação dos estudos sobre as sociedades da Alta Idade Média. É o caso, especialmente do Programa Transformation of the Roman World, da European Science Foundation (1993-1998), do qual participaram Stefano Gasparri (Universidade Ca'Foscari, de Veneza), Hans-Werner Goetz (Universidade de Hamburgo), Régine Le Jan (Universidade de Paris 1), Cristina La Rocca (Universidade de Pádua) e Rosamond McKitterick (Universidade de Cambridge). Os participantes desse programa em seguida ampliaram sua colaboração e empreenderam uma pesquisa coletiva sobre as transferências patrimoniais na Europa ocidental entre séculos VI e XI (1999-2002), que associou universidades francesas (Lille 3, Paris 1, Valenciennes e Marne-La-Vallée), italianas (Pádua e Veneza), a Universidade de Hamburgo e a Escola Francesa de Roma. É a partir desse programa que foi lançada o projeto coletivo sobre as elites na Alta Idade Média. Em que pesem essas inúmeras iniciativas, há ainda vários domínios de pesquisa a serem explorados no que se refere às sociedades da Alta Idade Média: a questão da articulação entre o simbólico e as práticas sociais, da dinâmica

33 WARD-PERKINS, Brian. The end of Rome and the fall of civilisation. Oxford/New York: Oxford University Press, 2005.

34 DEVROEY, Jean-Pierre. Économie rurale et société dans l'Europe franque (Vle-IXe siècles). Paris: Belin, 2003, t.1; DEVROEY, Jean-Pierre. Puissants et misérables. Système social et monde paysan dans l'Europe des Francs (Vle-IX siècles). Bruxelas: Académie Royale de Bélgique, 2006.

35 WICKHAM, Chris. Framing the Middle Ages. Europe and the Mediterranean, 400-800. Oxford: Oxford University Press, 2005. 
do espaço público, ou ainda o problema da função do ritual na criação das relações sociais. No Brasil, o atraso é ainda mais importante, não apenas em razão da pequena difusão dos trabalhos de especialistas da Alta Idade Média nas bibliografias dos cursos de graduação, mas também graças à importância desmedida das teses folcloristas, ao peso das perspectivas tradicionais, especialmente aquelas cujo centro de gravidade é o final da Idade Média. ${ }^{36}$

\section{A hipertrofia do "público"}

Para melhor ilustrar o que foi designado até aqui por especificidade das sociedades da Alta Idade Média, me deterei em um "topos" historiográfico específico: o das relações entre os domínios que, segundo as divisões do campo social, relevam do "privado" e do "público". Gostaria de começar pelas reflexões de Michel Rouche no primeiro volume da História da vida privada. A escolha de um livro publicado há cerca de um quarto de século pode parecer surpreendente. Ela se explica pelo sucesso dessa obra nas bibliotecas universitárias brasileiras, bem como no papel que desempenhou na formação dos estudantes brasileiros. Para tomar apenas o exemplo da Universidade de São Paulo (USP): as bibliotecas dessa instituição possuíam, em 2008, 135 exemplares dessa coleção de 5 volumes, publicada pela primeira vez no Brasil em 1991 e reeditada algumas vezes. Esses 135 exemplares estão repartidos nas diversas bibliotecas dos campi da USP, da capital e do interior - as edições em francês não entraram na conta. Mas retornemos ao texto de M. Rouche. O título de seu capítulo, publicado no volume 1 , resume a tese que ele sustenta ao longo dessas páginas: "a vida privada ao assalto do Estado e da sociedade". Segundo o autor, a privatização da vida social e política marcaria a Alta Idade Média, em oposição à Antiguidade romana: "Partout, en effet, depuis la cour jusqu'au dernier fonctionnaire, en passant par les groupes professionnels et religieux, de la ville à la campagne, personnes privées et espaces privés apparaissent au premier rang. La richesse elle-même devient affaire privée, et l'individu cherche à tout privatiser, sa maison comme sa table". ${ }^{37}$ Essa tese não é nova nem marginal. Desde o século XIX pelo menos, e em graus variados, os historiadores, especialmente na França, se habituaram em apresentar os primeiros séculos da Idade Média em termos que associam a instalação dos povos bárbaros, o desaparecimento da Res publica e o triunfo do

36 Sobre a formação dos medievalistas no Brasil, ver DE BARROS ALMEIDA, Néri. La formation des médiévistes dans le Brésil contemporain : bilan et perspectives (1985-2007). Études et Travaux. Bulletin du Centre d'Études Médiévales d'Auxerre, v.12, p.145-159, 2008; e sobre os estudos medievais no Brasil, CÂNDIDO DA SILVA, Marcelo. Les études en Histoire médiévale au Brésil: bilan et perspectives. In: http://ciham. ish-lyon.cnrs.fr/Brazil.html. (última atualização, juin 2006)

37 ROUCHE, Michel. La vie privée à la conquête de l'État et de la société. In: ARIĖS, Philippe e DUBY, Georges. (dirs.) Histoire de la vie privée. De l'Empire romain à l'an mil. Paris: Seuil, 1999 [1985], t.1, p.423-454. 
"privado" face ao "público". ${ }^{38}$ Tais ideias não estavam livres de segundas intenções nacionalistas: esses autores, que associavam os alemães aos bárbaros, acreditavam que esses últimos eram incapazes de compreender as abstrações do mundo greco-romano.

A partir de um retorno às fontes francas, gostaria de sustentar aqui um ponto de vista sensivelmente diferente: a especificidade da sociedade franca da Alta Idade Média repousa sobre a dificuldade em se distinguir o "público" daquilo que chamamos de maneira equivocada de "privado", e isso por razões que não derivam da preeminência dessa última. O que podemos compreender por "público" na Alta Idade Média? Responder a essa questão é algo bastante difícil e mereceria um estudo à parte. Nos limitaremos aqui a uma reflexão sobre a pertinência, ou não pertinência, do uso da dicotomia público"/"privado" para a sociedade franca da Alta Idade Média, a partir de alguns exemplos da prática judiciária dos séculos $\mathrm{VI}$ a IX, especialmente no tocante aos locais e modalidades das resoluções de conflitos e do problema da penitência.

No que se refere à resolução de conflitos, por exemplo, o único modo legítimo de reconciliação entre os litigantes era o mallus (assembléia judiciária), com a presença de um juiz (o conde ou o bispo). O Pactus legis Salicae (507?-511) previa, aliás, uma multa de 600 denários para aqueles que, uma vez instados a comparecer diante da assembléia judiciária, não o faziam. Mas havia uma exceção digna de nota: se aquele que havia sido citado estivesse ocupado em uma missão do rei, ele não pagaria a multa. ${ }^{39}$ O texto diferencia claramente esse caso daquele em que o citado está ocupado tratando de seus próprios assuntos; nesse caso, este é obrigado a comparecer. ${ }^{40}$ Isso cria uma hierarquia entre os "assuntos pessoais" e os "assuntos do rei", em benefício desses últimos. Além disso, o Pactus pro tenore pacis (texto real da primeira metade do século VI) associava a vítima ao acusado se a primeira aceitava a composição sem a presença de um juiz. ${ }^{41} \mathrm{O}$ critério da "publicidade" era, portanto, fundamental para instaurar a legitimidade da resolução de conflitos.

Os juízes da Alta Idade Média eram, da mesma maneira, obrigados a tornar públicos o segredo e o oculto ao longo do procedimento judiciário. No contexto do procedimento acusatório, mesmo se às vezes a reconciliação era mais importante do que a busca da verdade ou do que o triunfo de uma

38 É o caso, especialmente, de FUSTEL DE COULANGES, Numa Denis. La monarchie franque; LOT, Ferdinand. La fin du monde antique et le début du Moyen Âge. Paris: Albin Michel, 1989 [1a edição, 1927]; e também, HALPHEN, Louis. L'idée d'État sous les Carolingiens. In: À travers l'histoire du Moyen Âge. Paris, 1950, p.92-104.

$39 \mathrm{Nam}$ si in dominica ambascia fuerit occupatus, manire non potest. Pactus Legis Salicae, I, 1-5, ECKHARDT, KarlAugust. (ed.) MGH Legum, Sectio I: Leges Nationum Germanicarum, Hanover, v.IV, n.1, p.18-20, 1962.

40 Si uero infra pago in sua ratione fuerit, sicut superius diximus manire potest. Pactus Legis Salicae, I, 1-5, ECKHARDT, Karl-August. (ed.) MGH Legum, Sectio I: Leges Nationum Germanicarum, Hanover, v.IV, n.1, p.20, 1962.

41 Occulte sine iudice conpositionem fecerit. Pactus pro tenore pacis, 3, BORÉTIUS, Alfredus. (ed.) MGH Capitularia Regum Francorum, I, Hanover, p.5, 1883. 
parte sobre a outra, ${ }^{42}$ a revelação no espaço judiciário da intenção oculta subjacente à ação criminal constituía uma forma de "penitência pública" que impedia a desagregação dos laços sociais e ao mesmo tempo participava da afirmação da autoridade pública. É importante lembrar que todas as partes em litígio eram obrigadas a comparecer ao locus do julgamento, e isso diante do rei ou de um de seus representantes (juiz ou conde). ${ }^{43}$

É essa vontade de revelar o segredo dos atos criminais e o oculto de suas intenções que se encontrava na raiz das relações entre o poder judiciário e a autoridade divina na Europa franca. O ordálio, ou iudicium Dei, constituía um conjunto de provas físicas às quais se submetiam as partes em litígio, e nas quais o próprio Deus era chamado a revelar o inocente naquele que resistia à prova, ou o culpado naquele que sucumbia a ela. Os ordálios eram uma prática excepcional onde o julgamento de Deus era exposto visível e publicamente aos olhos e ouvidos de todos. O recurso ao iudicium Dei supunha também uma ampliação extraordinária do alcance da justiça, sem que, por outro lado, o foro interno dos sujeitos fosse reforçado: ele é, ao contrário, a principal vítima dessa justiça que rivaliza com a onipotência de Deus. Todas as verdades ocultas, a dos sujeitos e a do próprio Deus, deviam ser imperativamente reveladas aos juízes. A verdade do acusado e a da soberania divina se encontravam curiosamente em um mesmo plano, como mistérios que a autoridade judiciária tentava penetrar recorrendo a um procedimento excepcional.

Ainda que fossem um pouco dissonantes e até mesmo paradoxais em relação ao caráter conciliatório da resolução de conflitos da Alta Idade Média - daí sua excepcionalidade - os ordálios dependiam, para serem eficazes, de seu caráter público, da mesma forma que a penitência pública e as composições pecuniárias. A revelação do julgamento de Deus se fazia diante de numerosas testemunhas, especialmente os juízes, responsáveis de fato por interpretar e revelar o segredo de Deus e proclamar Seu veredito. Se, a partir do século XII, como mostrou Jacques Chiffoleau, começou-se a distinguir dois tipos de ocultos, o oculto absoluto (o dos iudicia divinos, inacessíveis ao homem) e o oculto que se pode e que se deve revelar, sobretudo quando a autoridade divina é ameaçada, no mundo franco da Alta Idade Média não era possível glosar sobre tais distinções. Tudo o que, de perto ou de longe, tocava ao imperativo da paz como condição da salvação poderia e deveria ser objeto de revelação.

As práticas penitenciais constituem outro observatório privilegiado da articulação entre "público" e "privado". A penitência, ou a remissão de pe-

42 BARTHÉLEMY, Dominique. La vengeance, le jugement et le compromis. In: Le règlement des conflits au Moyen Âge, Actes du XXX|e Congrès de la SHMESP. Paris: Publiations de la Sorbonne, 2001, p.11-20.

43 GREGÓRIO DE TOURS. Historiarum libri decem, VII, 47. Apud: B. KRUSCH e W. LEVISON, (eds.) MGH SS rer. Merov, Hanover, v.1, n.1, p. 366-368, 1951 (re-impressão 1965); Pactus legis Salicae, titulo I, ECKHARDT, KarlAugust. (ed.) MGH Legum, p.18. 
cados através do arrependimento dos erros passados, é essencialmente uma prática neotestamentária que se distingue progressivamente do batismo e que se difunde desde o século $V$ como um ritual público, destinado a reconciliar os pecadores com a comunidade de fiéis. Os historiadores têm tendência a apresentar a dicotomia entre "penitência pública" e "penitência privada" como um fenômeno tipicamente carolíngio, que teria surgido durante os concílios de 813, sem nunca existir na Gália merovíngia, na Espanha visigótica ou nos reinos anglo-saxões. A fórmula seria a seguinte: penitência pública para os erros públicos, penitência privada para os erros privados. ${ }^{44}$ Como mostrou Mayke de Jong, a expressão paenitentia privata é um anacronismo para a Alta Idade Média, na medida em que ele só se torna recorrente no século XII. Além disso, para designar a penitência que não é pública, os autores carolíngios utilizam a expressão paenitentia occulta. Não se trata de uma simples nuança ou de um capricho de taxonomia. A versão "oculta" da penitência permaneceu durante o período carolíngio uma categoria mal-definida nos cânones conciliares e nos capitulares, mais preocupados com a penitência pública. Em princípio, a paenitentia publica era uma prerrogativa episcopal, imposta a cada Quarta-Feira de Cinzas a todos aqueles que tinham cometido crimes ou pecados notórios contra a comunidade. ${ }^{45}$ Tornar-se publicamente um penitente era incompatível com a função clerical. Nos concílios visigóticos, a publicidade do pecado era o critério fundamental para julgar o próprio pecado e os pecadores: os bispos que tivessem confessado publicamente pecados mortais não podiam prosseguir na função episcopal. Segundo o IV Concílio de Toledo, aquele que confessasse manifesta scelera podia permanecer clérigo, mas não aquele que declarasse publicamente ter cometido um pecado mortal. ${ }^{46} \mathrm{Na}$ Gália merovíngia, o regulamento era ainda mais estrito. Durante o Concílio de Châlon (647-653), os bispos escreveram uma carta a Teodoro, bispo metropolitano de Arles, suspendendo-o de suas funções. A prática da penitência pública equivalia, para esses bispos, à retirada do penitente da comunidade de fiéis. ${ }^{47}$

44 É o que é apresentado no artigo de POIREL, Dominique. Pénitence. In: GAUVARD,Claude; DE LIBERA, Alain e ZINK, Michel. (dirs.) Dictionnaire du Moyen Âge. Paris: P.U.F., 2002, p.1071-1072.

45 Mayke, DE JONG. What was Public about Public Penance? Paenitentia publica and Justice in the Carolingian World. In: La Giustizia nell'Alto Medioevo (secoli IX-XI). Actas du XLIV Settimane di Studio del Centro Italiano di Studi sull'Alto Medioevo. Spoleto, 1997, p.863-902, aqui, p.865.

46 IVe Concile de Tolède, c.54. Apud: VIVES, Jose. (éd.) Concilios visigóticos e Hispano-Romanos. Madrid, 1963, p.204.

47 Epistula synodi ad Theudorium Arelatensem episcopum. Apud: GAUDEMET, Jean e BASDEVANT, Brigitte. (eds.) Les canons des conciles mérovingiens (Vle-VII e siècles). Paris: Cerf, 1989, v.2, p.564: Nam et scripta, qualiter uos constitit penitentiam fuisse professus, uestra manu uidemus e comprouincialium uestrorum manibus roborata. Vnde uos credimus etiam legisse nec nos paenitus ignoramus, quod, qui publice penitentiam profitetur, episcopalem cathedram nec tenere nec regere potest. Propterea salutantes beatitudini uestrae honorifique indicamus, ut usque ad allium sinodum de Arelatense sede, ubi uos constitit pontificalem cathedram tenuisse, debeatis omnimodis abstinere nec de facultate ipsius ecclesiae nihil ad uestram dominationem, dum in audientia ante fratres conueniatis, penitus presumatis 
Para os laicos, se a penitência pública também sancionava um erro cometido publicamente, ela constituía, por outro lado, uma forma de reparação do mal cometido e um meio de ser re-introduzido na comunidade de fiéis. O Concílio de Mâcon I (581-583) previa para o laico que havia acusado inocentes diante do rei ou de juízes (portanto, em uma assembléia judiciária) a privação da comunhão até a reparação, por meio de uma penitência pública, do mal que havia sido cometido. ${ }^{48}$

A paenitentia occulta não era objeto de uma definição particular nos textos judiciários francos. Ela era apenas uma categoria negativa, aquilo que não constituía a penitência pública. Se o pecado não causou scandalum, se ele não foi confessado diante de todos, e se o bispo não impôs como sanção uma penitência através de ritual público, a penitência era oculta, como sublinha Mayke De Jong. Da mesma forma, o pecado oculto era definido através daquilo que ele não era, ou seja, o pecado notório que comprometia a reputação de alguém, e não por meio da solidão das confissões. Os "pecadores ocultos" eram aqueles cujas reputações estavam intactas. Na sociedade carolíngia, como bem notou M. De Jong, o que contava era a penitência pública, a penitência pública representando tão somente uma categoria residual. Eram feitos esforços no sentido de preservar a reputação dos "pecadores ocultos", mas esses esforços eram muito mais um meio de refrear a publicação escandalosa do que a defesa da "privacidade" da confissão. Através da noção de scandalum, o estatuto da penitência pública ampliou-se a um conjunto de pecados públicos, ou seja, aqueles que violavam a ordem pública e a autoridade real. Na época carolíngia, por exemplo, o incesto e o parricídio foram incluídos entre os crimes para os quais uma penitência pública era prevista, pois eles eram vistos como um atentado à comunidade..$^{49}$ Isso mostra uma configuração particular do "espaço público", sua extensão para um domínio que apenas de maneira equivocada poderíamos designar com "privado".

Segundo Jacques Chiffoleau, não se pode sustentar a ideia de uma nítida separação entre o "público" e o "privado" na Alta Idade Média.50 Gostaria de formular a questão de outra forma: é precisamente a dicotomia "público"/"privado" que não é operacional para analisar as fontes desse período. Mais ainda: a indefinição da paenitentia occulta mostra que "aquilo que não era público" na sociedade franca da Alta Idade Média era permanentemente esvaziado de seu conteúdo, seja pelos imperativos da salvação (a exclusão dos pecadores da comunidade de fiéis), seja pela

48 Concílio de Mâcon I. Apud: GAUDEMET, Jean e BASDEVANT, Brigitte. (eds.) Les canons des conciles mérovingiens, v.2, p.428: De his uero, qui innocentes aut principi aut iudicibus accusare conuicti fuerint... si uero secularis, communiones priuabitur, donec malum, quod admisit, per publicam penitentiam digna satisfactione conponat.

49 DE JONG, Mayke. What was Public about Public Penance?, p. 863-902.

50 CHIFFOLEAU, Jacques. Ecclesia de occultis non judicat? L'Église, Le secret et l'occulte du XIle au XVe siècle. II segreto. Micrologus. Nature, Sciences and Medieval Societies, v.13, p.359-481, 2005. 
busca da verdade (os ordálios). Tudo ocorria como se o segredo, mas também o oculto ${ }^{51}$ e as relações interpessoais, fossem constantemente e muito paradoxalmente mobilizados e esvaziados por procedimentos que criavam e desenhavam as fronteiras de um "espaço público". Dessa apropriação do público e do oculto, das relações interpessoais e do segredo resulta talvez o equívoco de se apresentar a "privatização" como uma característica essencial da Alta Idade Média. Tem-se a impressão de que tudo o que é "privado" tomou de assalto o espaço público - para retomar a caracterização tão cara a Michel Rouche, quando é o espaço público quem procura invadir os domínios reservados do segredo e do oculto, expondo seus conteúdos à visão e à audição de todos.

É nesse sentido que se deve compreender, aliás, o fato de que a partir do século VIII os carolíngios se esforçaram para impor casamentos públicos. Encontramos uma tal prescrição no Concílio de Ver, em 755, que diz respeito tanto aos homens nobres quanto àqueles que não o são: $U t$ omnes homines laici publicas nuptias faciant, tam nobiles quam innobiles. ${ }^{52}$ Como sublinhou R. Le Jan, aos olhos dos clérigos e dos reis carolíngios, casamentos e dotes garantiam um casamento consensual e público, ou seja, legítimo. A difusão do dote acompanhou a luta das autoridades contra todas as outras formas de casamento, legítimas ou não, que não eram concluídas publicamente. O combate para impor o casamento público é um dos sintomas dessa hipertrofia do espaço público no mundo franco da Alta Idade Média.

Na Regra de Bento de Núrsia († c. 547), o claustro é a "casa" de Deus, o abade é o "pai" dos monges, e esses últimos são "irmãos". Esse vocabulário emprestado do registro carnal e doméstico designa aqui a organização de uma comunidade fundada sobre relações espirituais e não carnais, um patrimônio coletivo e um espaço partilhado. Muito se escreveu sobre o fato de que o vocabulário que designava os monges era oriundo de um registro carnal ("irmãos"), mas pouca importância se deu ao fato de que esses mesmos monges eram a representação de toda uma categoria social (os pobres). Além disso, a relação de amicitia entre os irmãos era regrada por ritos e cerimônias renovadas perpetuamente e diante de todos os membros da comunidade monástica, e ela se tornou um modelo para a

51 "Ces deux notions, le secret et l'occulte, dans la littérature juridique et dans les actes de la pratique judiciaire comme dans la plupart des autres sources dont disposent les médiévistes, sont tout à fait équivoques, ou au moins ambivalentes. Chargées à priori d'un sens négatif très marqué - l'occulte a toujours quelques liens avec le Diable et le secret avec le complot - elles servent aussi très souvent à designer ou même à qualifier une sphère qui au contraire n'a rien de négatif: celle de la connaissance réservée ou de l'inconnaissable. Une sphère qui peut même devenir superlativement positive lorsqu'elle concerne la toute-puissance divine et presque sacro-sainte lorsqu'elle touche au for interne de l'homme, accessible à Dieu seul, à l'abri de toute incursion extérieure (ce qui, à nos yeux de modernes, pourrait - sans doute un peu vite - en faire une préfiguration du sujet souverain contemporain)". CHIFFOLEAU, Jacques. Ecclesia de occultis non judicat? L'Église, Le secret et l'occulte du XIle au XVe siècle. I/ segreto. Micrologus. Nature, Sciences and Medieval Societies, v.13, p.359-360, 2005

52 Concilium Vernense (755). BORÉTIUS, Alfredus. (ed.) MGH Capitularia Regum Francorum, I, Hanover, p.36. 
sociedade. Assim, se a "casa" constitui um tema recorrente dos discursos morais e políticos da Alta Idade Média, isso se deve menos ao fato de que o mundo doméstico teria conquistado o espaço público, mas porque esse último se estendeu até o interior da "casa" - que se tornou, por sua vez, um locus exposto à visão e à escuta de todos - tomando-lhe emprestado seu vocabulário, as relações entre os seus membros e dando-Ihes um caráter público.

O vocabulário dos dois espaços - o espaço público e o espaço doméstico - se tornaram intercambiáveis. Na época carolíngia, até mesmo as relações interpessoais no seio da aristocracia podiam ser descritas segundo um vocabulário que pertencia ao campo semântico das relações políticas. O Manual de Dhuoda, escrito entre 841 e 843 por uma aristocrata da Septimânia para seu filho Guilherme, constitui um bom exemplo desse fenômeno. Dhuoda aconselha o seu filho a cultivar em primeiro lugar o amor de Deus, em segundo lugar, o amor de seu pai e somente depois ela menciona a necessidade de cultivar o amor do rei. Em que pese essa hierarquização que coloca o pai diante do rei, o vocabulário que a autora emprega para descrever a relação do pai e do filho não é aquele que tradicionalmente designa o amor filial, e sim a relação de dominação senhorial. No início do capítulo 12, Dhuoda afirma que ela ensinará a Guilherme o temor, o amor e a fidelidade que este último deve ao seu pai Bernardo: Qualiter domno et genitori tuo Bernardo, tam praesens quam absens, timere, amare, atque fidelis in omnibus esse debeas, insinuare, ut valeo, non pigeo. ${ }^{53} \mathrm{O}$ termo utilizado para designar o pai (dominus) é o mesmo que se utiliza no mundo franco desde o século VI para se designar os reis e os bispos. A relação entre Guilherme e Bernardo, tal como descrita por Dhuoda, não se restringe apenas ao fato de que esse último é o genitor, mas também ao fato de que ele é o senhor e, sobretudo, o responsável pela condição social de Guilherme.$^{54}$ Claro, as palavras de Dhuoda soam como um desafio para a elite carolíngia, ou seja, a afirmação de uma identidade e de uma superioridade "naturais" que justificariam uma posição (status) entre o rei que ela aceitava de servir e o populus que ela representava ao mesmo tempo em que o dominava. ${ }^{55}$ Mas há mais. Da mesma forma que o estatuto de Guilherme de que é questão nesse trecho do Manual não se restringe ao espaço doméstico, a paternidade não se constrói no segredo da casam

53 DHUODA. Manuel pour mon fils. Edição e notas, Pierre RICHE. Paris: Cerf, 1991 (Sources Chrétiennes, 225 bis), C. 12 .

54 DHUODA. Manuel pour mon fils, c.13 : "Certa quidem et fixa manet conditio quod nullus, nisi ex genitore procedit, non potest ad aliam et summam personam culmine pervenire senioratus. Ego autem admoneo te, desideratissime fili, ut inprimis diligas Deum sicut supra habes conscriptum ; deinde ama, time, et dilige patrem tuum, scitoque ex illo tuus in saeculo processit status".

55 LE JAN, Régine. Élites et révoltes à l'époque carolingienne: crise des élites ou crise des modèles ? In: BOUGARD, F.; FELLER, L. e LE JAN, R. (dirs.) Les élites au haut Moyen Âge. Crises et renouvellements. Turnhout, 2006, p.403423, aqui, p.403. 
mas segundo um vocabulário próprio às relações de poder. A paternidade era assim invadida por um vocabulário político, tornando-se algo mais do que simplesmente um atributo da domus aristocrática.

Não basta dizer que a uma supremacia do "privado", como sustenta a historiografia tradicional, sucede uma supremacia do "público". É necessário romper com essa dicotomia, e insistir sobre as especificidades do mundo franco na Alta Idade Média. Só havia lugar, nessa sociedade marcada pelos imperativos salvíficos, para um espaço público alimentado em permanência pelo esvaziamento constante do oculto e do segredo, tanto através do procedimento judiciário quanto através das práticas penitenciais. É, portanto, através da revelação desses erros (ordálios), na punição dos mesmos (penitência pública) ou na pacificação das partes em litígio (composição) que o espaço público era construído na Alta Idade Média. A abolição dos ordálios coincidiu, na segunda metade do século XII, com a publicação da Glosa do Decreto, de certas decretais pontifícias e com a atividade prática dos canonistas, que proclamavam que os juízes eclesiásticos não podiam interferir nos iudicia occulta divinos. Não é uma coincidência que isso ocorreu no mesmo momento em que a paenitentia privata fez sua aparição, designando um domínio à parte da prática da penitencial.

\section{Considerações finais}

Ao estudar a Alta Idade Média, não tenho a impressão de estudar as origens da Europa, menos ainda de olhar para as origens de meu próprio país. Estudar a história da Alta Idade Média significa sobretudo ser confrontado a sociedades radicalmente diferentes das nossas e cujo conhecimento não é um mero exercício identitário. Mesmo para os historiadores europeus, um tal exercício revelou-se, ao longo dos séculos XIX e XX tão perigoso quanto infrutífero. Como tudo leva a crer que a tese das origens medievais do Brasil constitui uma construção identitária ainda mais artificial que aquela que fez com que várias gerações de historiadores e eruditos franceses se referissem a "nossos ancestrais, os gauleses", não há nenhuma razão pare retê-la como justificativa para os estudos medievais no Brasil. Esses estudos não necessitam de âncoras identitárias, mas se inscrevem simplesmente no procedimento que nos conduz para o conhecimento do outro, das construções sociais distintas das nossas. Os historiadores franceses e alemães levaram algumas décadas para compreender que não era necessário disputar a herança romana ou germânica para escrever a história dos reinos bárbaros. Essa identificação com os romanos ou com os germanos só fazia sentido em uma paisagem historiográfica profundamente minada pelas paixões nacionais. Talvez eles ainda levarão algum tempo para descobrirem, da mesma forma, que os europeus, da mesma forma que os franceses ou os alemães, não existiam na Idade Média. De 
qualquer forma, nós não precisamos de forma alguma nos reivindicarmos da Idade Média para fazer desse período um objeto de estudos.

Por outro lado, reconhecer que o Estado moderno, ou ainda, que a Igreja, monárquica e centralizada tal como nós a conhecemos hoje, encontram suas raízes no final da Idade Média não constitui um procedimento identitário. O problema está no fato de que se adotarmos apenas esse ponto de vista como perspectiva para os estudos sobre aquele período, concentraremos nossos estudos apenas naqueles elementos que se prolongaram para além do período medieval. A questão é ainda mais complexa em se tratando da Alta Idade Média. Por não se querer reconhecer as especificidades desse período, ele foi visto apenas como o locus de uma forma de organização da sociedade política que seria mais tarde superada pelo Estado Moderno: durante muito tempo se acreditou que o "privado" havia prevalecido sobre o "público", como se essas fossem categorias operantes para o período e como se não tivesse ocorrido um esvaziamento constante em benefício do "público" dos domínios reservados do segredo e do oculto. É preciso romper com uma perspectiva que consiste a ver nos primeiros séculos da Idade Média a preparação da "feudalidade" ou da "civilização feudal". Ocupados demais em negar a originalidade da modernidade, em detrimento de uma Idade Média longa demais, alguns historiadores projetaram sobre a Alta Idade Média categorias elaboradas durante o processo de modernização, como foi o caso da dicotomia "público"/"privado". 